\title{
GENERACIÓN DE INGRESOS Y GERENCIA DE RECURSOS DESDE LA ECONOMÍA PÚBLICA TERRITORIAL EN COLOMBIA*
}

\author{
JAHIR ALEXANDER GUTIÉRREZ OSSA** \\ ESCUELA SUPERIOR DE ADMINISTRACIÓN PÚBLICA - ESAP
}

Recibido/ Received/ Recebido: 29-06 -2011 - Aceptado/ Accepted / Aprovado: 21-11-2011

\begin{abstract}
Resumen
Este artículo analiza la capacidad de generación de ingresos y gerencia de recursos de los entes territoriales, más allá de la estructura fiscal y presupuestal atada a la Ley 617 de 2000 (Presupuestal), la Ley 715 de 2001 (de Transferencias), la Ley 819 de 2003 (Responsabilidad Fiscal) y el Acto Legislativo 05 de 2011 (de Regalías). Se evidencia que el Estado central cuestiona el patrón de dependencia de los entes territoriales de los recursos girados por la nación, por el letargo provocado en su estructura fiscal y presupuestal. Para el análisis se considera la economía pública territorial, la cual permite contextualizar el asunto desde el esfuerzo fiscal y la estructura presupuestal. Se concluye que falta armonizar la estructura de la economía pública de los entes territoriales con miras a establecer un orden lógico de interacción con las expectativas fiscales y presupuestales centrales, sin desconocer lo problemático que es la generación de rentas y tributos territoriales.

Palabras clave: Capacidad fiscal territorial, Economía Pública Territorial, Finanzas Públicas y Macroeconomía, Política Fiscal Territorial

\section{INCOME GENERATION AND RESOURCE MANAGEMENT FROM TERRITORIAL PUBLIC ECONOMY PERSPECTIVE IN COLOMBIA}

\begin{abstract}
This article analyses income generation and resource management capacity of territorial entities, beyond fiscal and budget structure bounded to Act 617 of 2000 (budgetary), Act 715 of 2001 (transferences), Act 819 of 2003 (fiscal responsibility) and Legislative Act 05 of 2011 (royalties). It evidences that the Central State questions the dependency pattern of those entities in relation to resources provided by the nation due to lethargy caused in fiscal and budget structure. For the analysis, it is considered territorial public economy, which allows contextualizing from the interior of fiscal effort and budget structure. However, it still in arrears of harmonizing public economy structure
\end{abstract}

\footnotetext{
Este artículo es producto del proyecto de investigación: "Capacidades Institucionales Públicas para la Competitividad Territorial Internacional de las Sub-regiones del Departamento de Antioquia", financiado por la Vicerrectoría de Investigaciones de la Escuela de Administración Pública (ESAP). Investigación adscrita al Grupo de Investigación en Política, Derecho y Gestión Pública, registrado en Colciencias en categoría A, de la Escuela Superior de Administración Pública - ESAP-, Bogotá.

** Economista de la Universidad de Medellín, Colombia, (PHD) en Administración Pública, Atlantic International University (AIU), Hawái, (USA), Magíster en Desarrollo Regional y Local, Universidad Pontificia Bolivariana, Medellín, Colombia, Estudiante de la especialización en Sistemas de Información Geográfica (SIG), Universidad San Buenaventura, Medellín, Colombia. Docente e investigador, Facultad de administración, Universidad CES en Medellín y Universidad del Rosario en Bogotá, Colombia, Líder del grupo de investigación en Gestión Empresarial de la Facultad de Administración CES, registrado en Colciencias, y miembro, del Grupo de Investigación en Política, Derecho y Gestión Pública de la -ESAP-, Bogotá y, del Grupo de Investigación en Perdurabilidad empresarial en las empresas (GIPE) categoría A1 de la Universidad del Rosario, Bogotá. Correo electrónico: algutierrez@ces.edu.co.
} 
of territorial entities in order to establish a logical order of interaction with central fiscal and budget expectations. This last aspect classified as overwhelming as of rent generation and territorial tributes. Keywords: Territorial tax capacity, economy public Territorial, public finance and macroeconomics, Territorial tax policy.

\title{
GERAÇÃO DE RECEITAS E GERÊNCIA DE RECURSOS A PARTIR DA ECONOMIA PÚBLICA TERRITORIAL NA COLÔMBIA.
}

\begin{abstract}
Resumo
Este artigo analisa a capacidade de geração de receitas e de gerência de recursos por parte dos entes territoriais, para além da estrutura fiscal e orçamentária ligada à Lei 617 de 2000 (Orçamentária), à Lei 715 de 2001 (de Transferências), à Lei 819 de 2003 (Responsabilidade Fiscal) e ao Ato Legislativo 05 de 2011 (de Regalias). Evidencia-se que o Estado Central questiona o padrão de dependência dos entes com relação aos recursos enviados pela nação, por causa da letargia provocada na estrutura fiscal e orçamentária. Para a análise se considera a economia pública territorial, a qual permite contextualizar o assunto a partir do interior do esforço fiscal e da estrutura orçamentária. No entanto ainda se deve harmonizar a estrutura da economia pública dos entes territoriais com o fim de estabelecer uma ordem lógica de interação com as expectativas fiscais e orçamentárias centrais. Este último aspecto é catalogado como sufocante quanto à geração de rendas e tributos territoriais. Palavras chave: Capacidade fiscal territorial, Economia Pública Territorial, Finanças Públicas e Macroeconomia, Política Promotora Territorial.
\end{abstract}

Gutiérrez, J. (2011). Generación de ingresos y gerencia de recursos desde la economía pùblica territorial en Colombia. En: Revista de la Facultad de Ciencias Económicas de la Universidad Militar Nueva Granada. rev.fac.cienc.econ, XIX (2)

JEL: E62, E64, H21, H71.

\section{Introducción}

El poder de creación de los impuestos y tributos ha descansado generalmente en el Estado, quien al reglarlos constitucional, imponible y legalmente los convierte en fuente para la generación de recursos dirigidos a drenar los gastos e inversiones de los entes territoriales a través de la estructura departamental y municipal. Para ello, ha utilizado la hacienda pública (constitución y leyes), las finanzas públicas (gastos e ingresos) y la economía pública (capacidad, condiciones y fuentes) para equilibrar, proyectar y sostener los recursos de los entes locales.

Al evaluar el estado de los recursos girados a los entes y los resultados obtenidos con ellos, el Estado ha tenido la posibilidad de plantear un marco armónico de ingresos y recursos con respecto a la capacidad fiscal y presupuestal de los entes territoriales. La eco- nomía pública, tiende a mostrarse como herramienta de trabajo para que los entes estimen los mecanismos para generar recursos de orden local y regional. Es la ruta para evaluar la capacidad de los entes, para definir una estructura fiscal y de ingresos acorde con las estimaciones de orden central.

La búsqueda de recursos se ha convertido en el punto de referencia para los entes territoriales. Para los más optimistas, es la posibilidad de mostrar la casta pública en materia de gestión de recursos. Para los moderados, es la posibilidad de que se repiense la descentralización desde las fuente de los recursos y finalmente, no desde la destinación de tareas; para los pesimistas, es el camino final al que se ha llegado tras la descentralización, porque detrás de la búsqueda de recursos no todos los entes tienen la misma capacidad; escenario que puede llevarlos a perder la categoría y/o terminar adheridos a otros entes. 
Diversos estamentos centrales han indicado la necesidad de avanzar en el mejoramiento y saneamiento fiscal y presupuestal de los entes. En procura de ello, han sido corregidos los fundamentales con los que en algún momento se auspició directamente el apoyo estatal a ellos, en las que el Estado hacía las veces de fiador y prestamista. Hecho que aboco en una ola de acreencias territoriales que tuvieron que ser afrontadas al amparo del estado de emergencia económica (Decreto 2330 y 2331 de 1998), que dieron origen a las leyes y actos mencionados al inicio del escrito entre otros.

El artículo está compuesto en primer lugar por la revisión del desempeño fiscal y presupuestal de los entes territoriales trazado por el Departamento Nacional de Planeación (DNP) y el Ministerio de Hacienda y Crédito Público (MHCP). En segundo lugar, por la definición de los criterios requeridos para la generación de recursos nuevos. $Y$ en tercer lugar, del análisis que debe hacerse, si no se avanza en el mejoramiento de las finanzas públicas territoriales. El Estado ha dispuesto las reglas, ahora, la búsqueda del equilibrio fiscal y presupuestal está en manos de los entes territoriales.

\section{Desempeño fiscal y presupuestal de los entes territoriales en Colombia}

La constitución de 1991 impulsó a los entes territoriales a asumir una serie de compromisos y responsabilidades con cargo a la descentralización administrativa, contemplados bajo el suministro de recursos del orden presupuestal a través del nominado situado fiscal. El acceso a dichos recursos, sobresaltó en la mayoría de los casos a las administraciones públicas territoriales, acostumbradas a jugar un papel discreto en materia de desempeño fiscal, equilibrio y capacidad presupuestal, escenario predispuesto para el orden central. Exponen Afanador y Beltrán (2007, 113) que,

"La perspectiva de las finanzas públicas colombianas es bastante complicado si tomamos en cuenta que las once reformas tributarias avocadas en el periodo 19902004 tan sólo han logrado incrementar los recaudos en un $6 \%$ del PIB, con lo cual se ha incrementado la carga fiscal del $14 \%$ en 1990 a 20\% PIB en 2004, mientras que el gasto público se incrementó en $10 \%$ PIB en el mismo periodo, lo cual marca una tendencia inequívoca al desequilibrio fiscal de proporciones preocupantes."

El incremento del gasto público derivado de las nuevas responsabilidades fue asumido en principio, como un hecho connatural a las disposiciones constitucionales. Sin embargo, se había dado por descontado que la estructura administrativa $e$ institucional establecida para entonces no era suficiente. A la par con el ascenso de los recursos para gastos girados por el orden central, también se tuvo un importante incremento a la estructura burocrática justificada por cuenta de los requerimientos que con cargo al presupuesto incidió la contratación pública.

En contención a la situación, el Estado generó una serie de leyes como la Ley 80 de 1993 de contratación y, en consecuencia, otras como la Ley 42 de 1993 de control fiscal, dirigidas a ordenar el manejo de los recursos, cuyo carácter estaba dispuesto para observar el desempeño presupuestal de los entes territoriales con respecto a la ejecución dentro de los planes de desarrollo contemplados. Igualmente las Leyes Presupuestales (Ley 38 de 1989; Ley 179 de 1994 y la Ley 225 de 1995) que en comunión con Ley 152 de 1994 (Planeación); terminarían por ser compiladas en el Decreto 111 de 1996 sobre Estatuto Presupuestal. Ante esto Makon $(2000,6)$ plantea que:

"La relación que se genera entre la aplicación de la gestión por resultados y el presupuesto en los diversos países no es uniforme. No obstante, puede señalarse que todavía no existe una vinculación directa $y$ proporcional entre el desempeño de los organismos y su disponibilidad de recursos. En general, se observa que el intento está orientado en dos sentidos: por un lado, que el establecimiento de las metas esperadas sea consistente con la estructura presupuestaria correspondiente; por el otro, que la perspectiva de diseño presupuestario 
pueda ser extendida en años, permitiendo un horizonte de planificación más extenso, a la vez que aumentando los plazos de evaluación de la gestión por resultados del corto al mediano plazo. En consecuencia, la implementación de la gestión por resultados no constituye un modelo único ni se lleva a cabo de un modo predeterminado ni utilizando un conjunto dado de herramientas. Más bien, existen diferentes modalidades de implementar gestión por resultados, que dependen de las herramientas que se utilicen, el contexto político, social y económico en el cual el país se encuentre y la profundidad con que se pretenda aplicar el modelo."

El Fondo Nocturno Internacional en su momento recomendó con urgencia revisar el rumbo de la economía para evitar una posible desaceleración, prueba de que el recalentamiento económico estaba llegando a su fin. Las advertencias no fueron bien tomadas, tal vez, por el momento político internacional registrado en la administración Samper. Los datos macroeconómicos negativos corroboraron el momento, el cual trato de contrarrestarse con la Ley 358 de 1997, sujeta al artículo 364 de la constitución, con la cual se impuso límites al endeudamiento territorial frente a la capacidad de ahorro y pago de los entes. En contraste Cárdenas et al. $(2006,6)$ plantean que:

"Las finanzas públicas colombianas se caracterizaron por una gran estabilidad, incluso durante periodos de gran turbulencia para América Latina, como la "década perdida" de los años ochenta. Mientras el resto de la región presentaba un déficit del gobierno central cercano al $10 \%$ del PIB, en Colombia este desequilibrio no superó el 5\% del PIB. Sin embargo, esta situación cambió en la segunda mitad de la década de los noventa. Mientras que en la mayoría de países de la región las finanzas públicas se ajustaron con éxito, en Colombia ocurrió todo lo contrario (el déficit del GNC alcanzó niveles cercanos a 8\% del PIB en 1999), de manera que hoy en día este desequilibrio es superior al promedio de la región. De una situación fiscal balanceada en la segunda mitad de los ochenta, el gobierno central pasó a presentar déficit del orden de 5\% del PIB en promedio entre 2000 y 2005, lo que puso en entredicho su sostenibilidad fiscal, por lo menos hasta que se adoptaron algunos correctivos a raíz del programa suscrito con el FMI en 1999."

En ningún caso había sido advertido el desbarajuste que por cuenta de la creciente erogación presupuestal y las incesantes obligaciones asumidas por los entes territoriales, sumadas a la malversación de recursos impactarían sobre la capacidad del Estado central para hacer frente a los requerimientos locales. Estas circunstancias traerían consigo el desbordamiento del endeudamiento de los entes, que habían sido en su momento atendidos por cuenta de los empréstitos, financiación y giros dados por el Estado con cargo a la constitución pero que terminaron finalmente mellando la base fiscal. En complemento Gómez $(2007,139)$ sugiere que:

"La problemática de la deuda pública territorial no se ha solucionado de manera profunda, pues aún los niveles de endeudamiento son elevados en muchas localidades municipales; sin embargo, el gobierno nacional desde mediados de la década de los noventa ha dispuesto una serie de medidas para regular y controlar los factores que vulneran la estabilidad financiera y la viabilidad administrativa de los entes municipales."

Pasada la turbulencia política y asumida la credibilidad como un asunto del recién posesionado gobierno Pastrana, la declaratoria de emergencia económica no tardó en ser parte de central de las razones que impulsaron al gobierno a poner atención y vigilancia. Tras la emergencia, el país firmó un acuerdo de intervención con el FMI en el que se darían una serie de cambios importantes en los temas laboral, pensional, de salud y seguridad social, además de una clara disposición por parte del gobierno de prescindir de actividades que no respondían a su modo de ver parte de sus funciones. A este respecto Cárdenas et al. $(2006,17)$ plantea que: 
"La principal reforma reciente se introdujo por medio de la Ley 819 de 2003, mejor conocida como la Ley de Responsabilidad Fiscal (LRF), que buscó fortalecer la disciplina y sostenibilidad de las finanzas públicas. Aunque la norma tuvo su origen en las discusiones del gobierno colombiano con el Fondo Monetario Internacional en el marco del acuerdo extendido de 1999, también hizo parte de una serie de reformas encaminadas al saneamiento fiscal a todos los niveles de gobierno, iniciada con la Ley 358 de 1997."

El trabajo en adelante asumido por la administración Uribe en sus dos mandatos, consistiría en procurar que todos los entes territoriales asumieran la responsabilidad fiscal a través de la Ley 819 de 2003 en congruencia con la Ley 42 de 1993 de control fiscal entre otras, para hacer de la gestión presupuestal una tarea de todos, entre estos, los organismos de control, auditoría, contraloría, fiscalía y procuraduría ajenos para entonces de estos temas. De allí, se determinó que los entes territoriales definirían sus gastos en el corto plazo y definirían un marco de ingresos establecidos en el denominado Marco Fiscal de Mediano y Largo Plazo. Lo que analiza Bonet (2004, 9) así:

"El vínculo teórico entre descentralización $y$ desigualdades en los ingresos regionales puede establecerse en dos diferentes marcos: descentralización fiscal pura y no pura. En el sistema puro, los gobiernos locales recogen sus propios impuestos para financiar sus gastos sin el beneficio de las transferencias del gobierno central. Por otro lado, un sistema no puro está compuesto de gobiernos locales que tienen la responsabilidad de asignar recursos sin ninguna obligación por el lado tributario. El recaudo de impuestos lo lleva el gobierno nacional, quien posteriormente transfiere los recursos a los gobiernos subnacionales de acuerdo con determinados criterios."

La responsabilidad fiscal tomó por sorpresa a las administraciones públicas territoriales para las cuales el saneamiento fiscal hacía parte de las tareas propias de su gestión, pero que con respecto al control y vigilancia de los recursos públicos no tenían las herramientas suficientes para hacer dicha labor. Para dicho momento, el número de contralorías aumento rápidamente, pero sin premisas claras hacia donde apuntar. Esto por cuanto el tema no solamente era administrativo o legal, para ello era más que necesario provocar un interés político y público en el tema. De este mal o este hecho mostró que la cantidad de estamentos no implicaban más control. Esto lo puntualiza Cano $(2007,23)$ diciendo que;

"Si bien el proceso de descentralización otorga competencias y recursos a las entidades territoriales para proveer los servicios sociales básicos para la población, el desempeño global aún dista mucho de mostrar los niveles de eficiencia necesarios, cuando se constatan los insumos utilizados frente a los recursos obtenidos. Esto por problemas de gestión, utilización de insumos u obtención de productos. Ello no quiere decir que la descentralización fiscal conduzca a un Estado ineficiente, sino que debe trabajar aún más en la consolidación de una administración pública territorial que muestre competencia técnica, organización administrativa y niveles de gestión pública acordes con las metas establecidas en los planes de desarrollo de las entidades territoriales, emulando a las entidades territoriales eficientes y mejorando su gestión."

Las administraciones públicas territoriales desde todos los frentes recibieron los embates sugeridos por el FMI para corregir el desequilibrio económico, escenario que sirvió para modificar lo estipulado en la constitución 1991. Tras dichos cambios, las entidades territoriales tuvieron que continuar respondiendo sus obligaciones con menos recursos en términos reales, pues la corrección monetaria prevaleciente para la época como instrumento de ajuste fiscal que daba cierto aire al manejo presupuestal había cumplido su ciclo. En adelante, el presupuesto dependería del incremento de los ingresos reales del Estado (Ley 617 de 2000). Restrepo \& Álvarez $(2005,36)$ argumentan al respecto que: 
"El proceso de ajuste del sector público colombiano llevado a cabo por las autoridades económicas, especialmente a partir de la segunda mitad de la década de los años 90, generó efectos positivos sobre el balance fiscal de los GCT. Gracias a las normas que racionalizaron el acceso de los gobiernos subnacionales al crédito con el sistema financiero, que favorecieron la reestructuración de pasivos de las entidades y el mayor recaudo de ingresos tributarios para los departamentos, y que impusieron limitantes al $G f$ de los gobiernos centrales, el sector público territorial registró por primera vez en muchos años un superávit fiscal en 2004 que significó casi un punto del PIB al totalizar más de $\$ 2,3$ billones."

El nuevo gobierno del presidente Santos, en su plan de desarrollo sobre prosperidad democrática, le apuesta a la dirección de un Estado serio comprometido con el buen destino y uso de los recursos públicos. En este, procura que los entes territoriales entren a evaluar bajo orden estatal la forma como terminan siendo utilizado estos recursos. Acusando también que si no ve cambios en cuanto a la responsabilidad territorial en el manejo de los mismos, hará los ajustes necesarios, como en el caso de las Regalías (Acto Legislativo 05 de 2011) para que estos sean parte de la canasta de fuentes para mejorar el desempeño presupuestal de los entes territoriales. Clavijo \& Vera $(2010,33)$ sustentan que:

"En síntesis, Colombia enfrenta serios desafíos fiscales en el próximo cuatrienio. En el contexto de América Latina, sus indicadores fiscales se encuentran ligeramente arriba del promedio. Cuando se detallan los niveles de ingresos y gastos se encuentra un desfase primario del $1 \%$ del PIB resultado de una baja presión tributaria y de unos gastos inflexibles a la baja y con presiones al alza. De allí la urgencia de acometer sustantivas reformas estructurales, tanto en el plano fiscal como laboral, especialmente si queremos recuperar el "grado de inversión" que perdiéramos en el período 1998-1999."
Los ajustes en las entidades territoriales no se han hecho esperar tanto en lo relacionado para responder al llamado generalizado de orden la administración pública local y regional desde el buen manejo en materia de los recursos públicos. La disposición de un extenso orden jurídico permite en la actualidad estimar que, de seguir los lineamientos sobre los que está trazada la política fiscal y presupuestal del país, como en el caso de la adopción de la regla fiscal, en conjunto, con el interés territorial de avanzar en materia de saneamiento fiscal (mejoramiento en la distribución e impacto de las regalías), los resultados que se esperan en cuanto al equilibrio de la economía pública están por alcanzarse para bien de la viabilidad de los entes y de las posibilidades de la población en general. Lo que contextualiza el Ministerio de Hubiera y Credito Público $(2010,30)$ al plantear que:

"La adopción de una regla fiscal para el manejo de las cuentas públicas permite asegurar un nivel sostenible de deuda pública, facilita el manejo contra cíclico de la política fiscal, así como la coordinación fiscal y monetaria, aspecto fundamental en el diseño de la política económica. Así mismo, se espera que contribuya a aliviar los efectos de la volatilidad cambiaría sobre diferentes actividades de la economía, en especial el sector transable, en la medida en que una administración eficiente de los recursos excedentarios que se generen por un posible auge minero-energético. Estos objetivos redundan en beneficio de la población y del fortalecimiento del Estado Social de Derecho."

Es el momento para que los entes territoriales desarrollen y promuevan alternativas que les permitan determinar la composición fiscal y tributaria a la que pueden estar expuestos sino se hacen los correctivos necesarios. Esto en cuanto a la armonización y correspondencia que debe establecerse entre la estructura territorial y las pretensiones que con cargo a ellas extienda el Estado central. La dilación reinante puede traer dificultades en particular para los entes territoriales, porque a pesar de la voluntad política y la disposición legal para que puedan avanzar en el tema, la responsabilidad recae directamente en manos de los alcaldes y gobernadores, que deben 
estar atentos a la posibilidad de allanar fuentes de recursos distintas a las tradicionales.

\section{Economía pública territorial, generación de ingresos y gerencia de recursos territoriales}

La economía pública atraviesa la composición estatal, estamental y gubernamental de la estructura que compone la generación de recursos para la administración central y territorial. Constituye el armazón para lo cual el Estado pretende definir claramente unas condiciones que permitan ordenar el espacio sobre el cual se pueda avanzar en la generación de los mismos. Esto supera la prueba de acierto-error que con cada paso se atiende con cada reforma tributaria. Tambien se convierte en un mecanismo de actualización financiera de los entes territoriales a través del levantamiento de información y datos con fines de generar nuevos recursos. Márquez y Silva (2008, 151) exponen que:

"Esta área de la economía o de economía aplicada, denominada en principio -finanzas públicas, ha empezado a designarse, desde los años setenta del siglo XX, -economía pública. En principio trató los mismos problemas, más allá de las limitaciones presupuestales de ingresos, gastos y deuda pública. Y posteriormente, amplió su campo de análisis a los bienes públicos, a la incidencia de los impuestos y gastos en el bienestar, a los efectos de las regulaciones públicas, los derechos de propiedad, el problema de las externalidades y los procesos de toma de decisiones públicas."

No significa que se haya presentado un agotamiento de la hacienda pública como entramado estatal o de la consideración de las finanzas públicas como vertiente de las condiciones macroeconómicas. Se trata de equilibrar la capacidad de carga territorial de los entes con la disponibilidad de recursos, para lo cual, se requiere que estos realicen un esfuerzo fiscal importante, que no sólo se ejecute vía desembolso o ejecución de recursos sino con la generación paulatina de recursos propios, que es en últimas en donde están sembradas las expectativas de la economía pública. Lo que fundamentan Rentería y Echeverri $(2006,27)$ al afirmar que:

"En Colombia, a diferencia de otros países que también optaron por programas acelerados de descentralización fiscal, las finanzas territoriales no constituyen actualmente una presión fiscal exagerada. Desde mediados de la década de los noventa, apenas se vislumbraron problemas potenciales, en ese frente, se fueron tomando decisiones que han resultado en unas finanzas territoriales a todas luces positivas. Se establecieron señales de alerta temprana para identificar y actuar sobre problemas en gestación, se definieron reglas y límites al gasto y su relación con los ingresos y se especificaron reglas sostenibles en materia de las transferencias."

Al invitar a los entes territoriales a participar de las ventajas constitucionales y jurídicas en materia de atracción recursos, contrario a lo señalado, no es un centralismo arropado; es la posibilidad de que se repiense la condición geográfica como estructura para consumar inversiones y proyectos que representen para los territorios la posibilidad de que lleguen nuevas formas tributarias o ingresos con los cuales el estímulo central se vea compensado a la par que redirigido, en la medida en que los ingresos nuevos procreen otras posibilidades de inversión. Argumenta Montecinos $(2005,75)$ que:

"La descentralización, desde la perspectiva fiscal, ha adquirido un gran consenso incluso en países con una larga tradición centralista. Este consenso se ha alcanzado en materia de decisiones y relaciones intergubernamentales de carácter fiscal del Estado-nación con los niveles subnacionales debido, entre otras cosas, al ambiente cada día más competitivo al cual se enfrentan los gobiernos nacionales y sub-nacionales."

El atractivo de la ley que permite la relación económica pública entre dos o más territorios, es precisamente el de advertir en ejercicio las opciones que unidos podrían tener, partiendo de escenarios concretos, por 
cuanto lo público así lo exige, o de la visibilización de alternativas que hasta ahora no han sido definidas por cuenta del estado unitario que aún se plantea en cada territorio en aras de la conservación y protección administrativa, que hoy se encuentra más que endeble por la movilidad de los actores y sujetos que hasta hace poco representaban discrecionalmente la generación de ingresos para los entes territoriales. El DNP (2005, 40-41) plantea que:

"Por otra parte, el Departamento Nacional de Planeación (2004)22 al calcular un modelo de eficiencia y establecer las mejoras potenciales, señala que los municipios podrían alcanzar un recaudo potencial cercano a $\$ 1$ billón, concentrado especialmente en municipios de categoría especial, primera y segunda, para los impuestos locales, principalmente predial e industria y comercio. El objetivo de dicho estudio fue evaluar la magnitud del recaudo comparado con los gastos de funcionamiento de los municipios, bajo la premisa de la Ley 617 de 2000 de que mantener más gatos de funcionamiento implica recaudar más rentas propias para poder sufragarlos. En este sentido, se encontró que la mayor parte de los municipios mantienen estructurales fiscales particulares que hacen que el recaudo relativo no pueda ser el que alcanzan las ciudades y departamentos grandes. En unos casos, esta situación se debe a factores de gestión, mientras que en otros casos se debe a factores políticos, geográficos y de base económica."

El comportamiento de la actividad económica ha sido el punto de referencia a la hora de definir la estructura y el marco fiscal con la capacidad presupuestal central y territorial. Ahora bien, corresponde al Estado disponer de los elementos constitucionales y legales para que las administraciones públicas territoriales entes constituyan la base fiscal para que estos puedan acomodarse. En este sentido, la forma como sea referida la estructura tributaria en el orden nacional directamente facilita o impide que haya celeridad en la materia a escala territorial desde la economía pública. Lo que reiteran Márquez y Silva (2008, 171) diciendo que:
"El término economía pública, del mismo modo que sus ideas originales, parece haber sido acuñado en Francia, una economía de mercado dotada por una historia con un gran sector público, importantes empresas públicas, un servicio civil e instituciones éticas, una ideología que favorecía un papel económico para el Estado, y cuerpos de inteligencia-pública matemáticamente orientada a la dirección del Estado."

La economía pública es el escenario para que las administraciones busquen alternativas con las cuales pueden mejorar en su gestión. De manera complementaria, en ella se trata más que de menoscabar en el Estado burocrático o de elección pública, la posibilidad de que la administración realmente tienda a buscar alternativas que superen la dependencia del orden estatal y de los entes derivados de éste. Sin embargo, la revisión de la capacidad de generar recursos está a la vista, para lo cual la mayoría de entes no salen bien librados, teniendo que recurrir a permanecer o desaparecer, según las circunstancias al margen de la discrecionalidad del Estado. En este sentido, Cadaval $(2005,229)$ sugiere que:

"La economía pública local y, fundamentalmente, la hacienda urbana, constituye un ámbito de estudio que ha ido cobrando fuerza a lo largo del tiempo, debido a que no sólo se vive el mundo del federalismo fiscal a través de la literatura especializada, sino que esta realidad se ha convertido en el entorno institucional del que se han dotado buena parte de los países."

El trabajar juntos parecer ser el llamado del Estado con las entidades territoriales, llamado sobre el que se pone a prueba la resistencia de los entes para soportar la andanada de exigencias que vendrán. La respuesta parece descansar en la capacidad de gestión y resultados que por cuenta propia puedan generar. Lo interesante del asunto, es que aún no es claro el panorama para los entes territoriales los cuales se encuentran presos de una baja probabilidad de crear impuestos de cualquier vertiente, pero si, están abiertos para generar ingresos que les permitan alternar los recursos de la nación con los propios 
para mejorar la gerencia pública en temas como los servicios públicos, la habitación, el medio ambiente, la movilidad, la contaminación, la explotación de recursos entre otros, que los hace llamados a orientar su propio futuro, y según lo expone Guadarrama (2003, 143):

"La gerencia pública es una alternativa al paradigma burocrático que se articula en la convergencia sobre la incorporación de modos de gestión privados a las organizaciones públicas, en la promoción de las ventajas de los comportamientos gerenciales, en la estructuración de nuevos esquemas de relaciones y en la necesidad de transformar en más eficientes y rentables las acciones públicas. La puesta en relieve de las características que constituyen parte del corpus distintivo de la gerencia pública refiere al modelo conjunto de estrategias que busca mejorar la gestión y la administración, pero que no necesariamente cuestiona la estructura y funciones del Estado, la pertinencia de los fines de la política o su atingencia para los problemas que pretende resolver."

No ha sido suficiente el buen desempeño que han mostrado las administraciones locales en cuanto al manejo dado a los ingresos y gastos, relación contable que devela un cambio de dirección en la forma como los departamentos y municipios hacían uso de los recursos públicos. En una época en la que el exceso de gasto provenía de éstas instancias institucionales, y a la cual el Estado atendió a medida que la constitución lo exigía, a la cual sin embargo le aplico correctivos, en la actualidad estos entes arrojan resultados positivos en comparación con el desempeño del Estado central en la materia. Restrepo \& Álvarez $(2005,37)$ complementan lo anterior planteando que:

"Entre 1995 y 2003 la estructura de los tributos de las gobernaciones perdió más de cuatro puntos de participación frente a los ingresos totales, los cuales fueron ganados por las transferencias. Los gastos de funcionamiento, si bien mostraron una tendencia decreciente en los últimos años, todavía tienen un peso relativo muy importante dentro de los gastos totales, resultado en el cual la burocracia estatal en contralorías y asambleas alcanza una significativa participación. En el plano local, los municipios reflejan un comportamiento más o menos similar al de los gobiernos departamentales. La estructura tributaria local es poco sólida y se caracteriza por un cierto repunte en algunos años para luego registrar una pérdida de participación. Las transferencias siguen siendo el motor que lidera los ingresos de los municipios, lo que permite concluir que sin ellas sería imposible atender los pagos y compromisos, por cierto todavía concentrados en gran medida en los gastos de funcionamiento."

En la actualidad, todos los organismos de control, fiscalización y vigilancia están más sobre esta nueva realidad que en poner en jaque cualquier maniobra que pretenda defraudar al fisco, y por ello, se ha vuelto a revisar las ventajas tributarias otorgadas en años anteriores. La nación. Mostrando con ello, la imperiosa necesidad de abordar la eficiencia en el manejo de los ingresos y gastos como un asunto de carácter nacional, en el que todo el establecimiento debe estar presto para responder, independiente a la posición que ocupen o el matiz de su actividad. Por ello, este gobierno ha tomado la lucha contra la corrupción como una de sus promesas de campaña. A manera de ejemplo Muñoz $(2002,56)$ escribe:

"La aplicación de esquemas modernos de Gerencia Pública Municipal cobra, cada día, mayor importancia en la gestión de las diferentes Administraciones Municipales del país. No obstante lo anterior, sus resultados todavía son incipientes; de hecho, sus mejores desarrollos se encuentran localizados en las ciudades capitales. Múltiples factores inciden en este comportamiento: los altos niveles de influencia de la política tradicional, los bajos perfiles profesionales de los gerentes públicos, la escasa cultura de la planeación técnica del desarrollo, la ausencia de sistemas adecuados de indica- 
dores de gestión, el recrudecimiento de los niveles de violencia, producto del conflicto armado, entre otros. Esta compleja problemática se refleja en los altos niveles de endeudamiento, bajos índices de esfuerzo fiscal, pervivencia del fenómeno de la corrupción, deterioro de los niveles de calidad de vida de los habitantes, etc."

Al elevar la estructura fiscal y de manejo presupuestal al estado de gerencia pública la idea es poder incentivar a la administración pública a internalizar los fundamentos que representan la gestión de los recursos como parte de los resultados que igualmente deben dar los entes en temas como la planeación para el desarrollo. No obstante, la generación de ingresos territoriales ha estado contemplada de manera marginal conforme al comportamiento de las finanzas y el presupuesto estatal central, argumento que ha valido para que los entes locales acusen incapacidad de maniobrar ante la atomización impositiva creada por el marco fiscal, presupuestal y tributario diseñado desde las perspectivas de las arcas públicas estatales con poca adherencia a los requerimientos locales.

\section{Equilibrio y responsabilidad de los entes territoriales en la generación de recursos propios}

Los entes territoriales han asumido cuesta arriba las exigencias que desde el Estado central han sido formuladas para ordenar el presupuesto público del país. Es visto, que tras de dichas transformaciones, progresivamente se vienen compulsando una serie de ajustes y reglas que predisponen a los entes para que su gestión sea eficiente y muestren resultados concretos, apelativo que aún no termina por calar en los mismos, por la dependencia a ultranza de lo que pueda hacer el Estado central en términos de generación y distribución de los recursos. Hernández interpreta $(2006,4)$ que:

"Esta mejora en la gestión pública es producto de tres factores que vale la pena resaltar: i) el proceso de saneamiento contable que se llevó a cabo en los últimos años; ii) el impacto de los planes de mejoramiento que han adoptado las entidades por exigencia de la CGR y iii) una mayor atención de las directivas de los entes estatales, particularmente en el campo del control interno."

La responsabilidad en todos los frentes no es de estricta constipación para el Estado central, en suma, los entes deben responder directamente por el destino que hacen de los recursos que por regalías o transferencias reciben o de lo contrario, serán sancionados desde todos las instancias. Detrás de los malos manejos viene acusándose el afianzamiento de la corrupción y otros vicios en contra de la eficiencia territorial. Frente a estos postulados, se busca que los entes territoriales superen el estado de dependencia y muestren resultados no sólo con el gasto público, sino con la generación de ingresos en niveles de ser posible uno a uno, para que con el tiempo los resultados económicos y sociales sean visibles. Lo que explica el Departamento Nacional de Planeación $(2005,43)$ de la siguiente forma:

"El debate sobre el efecto que tienen las transferencias en el fortalecimiento de los ingresos tributarios de los gobiernos locales se suele denominar esfuerzo fiscal. En resumen, el debate se refiere a si las transferencias que realiza el gobierno nacional a los gobiernos territoriales estimulan o no la generación de recursos propios, como contrapartida a tales recursos. Si el efecto es positivo, se habla de la existencia de esfuerzo fiscal, mientras que si es negativo, se entiende que hay pereza fiscal. Este último caso se da porque, en general, existe la tendencia de los gobiernos locales a preferir las transferencias gratuitas de los niveles superiores de gobierno que a asumir los costos políticos de incrementar los impuestos. De este planteamiento se deduce que la transferencia de recursos reduce el esfuerzo tributario territorial porque los gobiernos locales minimizan los costos políticos y administrativos que puede significar un alza en las tarifas o la imposición de mayores impuestos. No obstante esta con- 
ceptualización, conviene señalar que los estudios empíricos aplicados a Colombia no presentan evidencia de pereza fiscal y más bien, la tendencia es a concluir que los departamentos y municipios han evidenciado esfuerzo por incrementar sus recursos propios en términos reales, a pesar de que existen limitaciones metodológicas y de información que en algunos casos muestran resultados encontrados. También hay evidencia de que los gobiernos locales han utilizado las transferencias para los propósitos que les fueron otorgadas, es decir, se ha evidenciado un crecimiento del gasto social en la misma dirección del incremento de las transferencias recibidas."

El llamado para que todos los entes territoriales alisten sus opciones, es un llamado a la reflexión en cuanto a la ruta tomada por cada uno de ellos para convencerse que el ejercicio de la buena administración pública no está trazado en el derrotero de la ley, sino en la capacidad de trabajo que se aplique en los mismos. De ahí que, hoy en día hayan más miradas puestas en la labor desempeñada en estos entes, que si bien es cierto, cuentan con organismos de control y vigilancia, tienen acuestas la revisión del Estado central para reorientar o sancionar sus acciones. De manera clara, es una convocatoria que hace el Estado para que los recursos de la nación sean bien administrados, y según lo indica Muñoz $(2009$, 39):

"Es el momento de pensar en una descentralización espacial orientada a la apertura de espacios que promuevan el desarrollo desde nuestras regiones. Este enfoque requiere una mirada más integral del proceso de descentralización en Colombia. Tal vez sea el momento de ver nuestras regiones considerando sus diferencias, los desequilibrios económicos y sociales que hoy se presentan entre regiones y la débil estructura institucional con que hoy cuentan departamentos y municipios para promover procesos de desarrollo económico y social, más allá de la simple provisión de los servicios sociales. Sin embargo, Colombia a pesar de ser un país de regiones, no ha contado con una verdadera política de desarrollo regional, que considere lo territorial como dimensión determinante en el desarrollo."

Los departamentos y municipios son quienes tienen la vocería en este aspecto, para responder o para superar la dependencia del Estado central. Para el efecto, los cambios en la legislación con el Sistema General de Participaciones, en el que el Estado continúa siendo solidario en algunos temas, pero a cambio, pide resultados tanto en calidad como cobertura, mezcla que impone y exige a las administraciones territoriales acciones concretas y no disipadas, en las que en ellas puedan verse reflejadas la relacione entre los recursos desembolsados y la planeación para ellos puesta en marcha.

"El acto legislativo 01 de 2001. Este Acto legislativo creó el Sistema General de Participaciones (SGP) de los departamentos, distritos y municipios, con base en los recursos del situado fiscal, el Fondo Educativo de Compensación (FEC)10 y la participación de los municipios en los ICN. Destinó los recursos a la financiación de los servicios a cargo de las entidades territoriales respectivas, "dándole prioridad al servicio de salud y los servicios de educación preescolar, primaria, secundaria y media, garantizando la prestación de los servicios y la ampliación de cobertura". Así mismo, ordenó que las entidades territoriales indígenas serían beneficiarias del sistema lo mismo que los resguardos indígenas, mientras no constituyeran entidad territorial. Los criterios de distribución fueron identificados así: para educación y salud, la población atendida y por atender, reparto entre población urbana y rural, eficiencia administrativa y fiscal y equidad. Para otros sectores: población, reparto entre población urbana y rural, eficiencia administrativa y fiscal y pobreza relativa" (Contraloria General de la República, 2006, 17-18).

Para el análisis en cuestión, se toma en cuenta las propuestas relacionadas con la asociación de los entes territoriales, la posibilidad de generar recursos 
propios o el espíritu que de la economía pública debe insertarse en la administración territorial, departamental y municipal, bajo las cuales es necesario que empiecen a llevarse a cabo programas y proyectos de naturaleza interterritorial con las cuales pueda refrendarse que uno de los principios del presupuesto público es la complementariedad territorial, lo que en su efecto ha tenido por nombre el principio de homeostasis. Al respecto expone $\operatorname{MHCP}(2010,3)$ que:

"Cumplir con el principio de coherencia macroeconómica que ordena el EOP, y su consistencia con el MFMP que adopta una postura fiscal responsable, enmarcada dentro de la propuesta de "regla fiscal", para garantizar la sostenibilidad de las finanzas públicas en el mediano plazo y permitir una reducción gradual de la deuda en cabeza del Gobierno Central."

La asociación territorial entre departamentos y municipios parece ser la tendencia que promueve el Estado central, partitura que viene postulada desde la misma constitución de 1991, que considera viable la unión de estos para aprovechar convergencias que permitan la complementariedad de recursos entre ellos. Los departamentos que guardan correspondencia geográfica y económica, por su cercanía territorial y por las actividades productivas que comparten son los llamados a aprovechar el espacio dado por la constitución y la ley para reorientar sus finanzas y recursos desde la convergencia fiscal territorial que impulsaría la escenificación de una puesta en común entre departamentos o municipios. Explicando García $(2011,3)$ sugiere que:

"Haciendo uso del artículo 306 de la Constitución Política de 1991 que reza "Dos o más departamentos podrán constituirse en Regiones Administrativas y de Planificación, con personería jurídica, autonomía y patrimonios propios.”

En atención a la oportunidad de obtener recursos por cuenta propia las administraciones departamentales y municipales, deben reconsiderar los pasos que deben seguir para indagar acerca de la dimensión que tiene cada uno de los entes en tanto puedan definir- se sobre que rubros y recursos definir las fuentes de ingresos. Se requiere de un trabajo pleno para que los entes evalúan en perspectiva sobre que campos y tópicos podrían dar espacio para que la probabilidad de búsqueda de recursos, por lo menos, tenga un camino de análisis cierto pero que necesariamente obliga la participación de todos los entes en cada departamento y municipio. Esto lo analizan Zapata et al. (2001, 12-13) diciendo que:

"En el caso de los departamentos, los ingresos tributarios adolecen de una alta inelasticidad ingreso, a diferencia de las fuentes de financiación de los municipios y de la Nación que responden al comportamiento de la economía. Los ingresos de los departamentos, derivados del consumo de bebidas alcohólicas y tabaco no dependen del desempeño de la economía, y su comportamiento se ha visto altamente afectado por el contrabando. En los últimos años se avanzó en la adopción de medidas orientadas a romper con ese esquema con la creación de la sobretasa a la gasolina y al ACPM, un tributo elástico al crecimiento de la economía, que ha mejorado el ingreso en algunas regiones.(...)

En el caso de los tributos municipales la base tributaria está constituida por impuestos a la tenencia de predios, al desarrollo de actividades comerciales $e$ industriales y a la circulación de vehículos particulares, fundamentalmente. Las características de estos impuestos han hecho que la posibilidad de recaudo sea diferente según el tamaño de los municipios. Por ejemplo, en los municipios capitales el recaudo de industria y comercio tiene mayor dinamismo que en los municipios pequeños en los que estas actividades tienen menos presencia. Algo similar sucede con el impuesto de tránsito y circulación de vehículos que favorece en términos de recursos a las ciudades grandes más que a la mayoría de municipios, pues la mayor cantidad de vehículos se concentra en estas ciudades. Por otro lado, el predial unificado es un impuesto que está 
supeditado a un mecanismo centralizado de cobro; a excepción de ciudades como Bogotá, Cali, Medellín y los municipios de Antioquía que tienen sus propios mecanismos de catastro, lo que genera desactualización y lentitud en el recaudo."

La incursión generalizada de los departamentos en otros frentes, es un ejemplo en el cual se pueden diseñar estrategias departamentales como las escuelas de gobierno o los fondos de inversión de capital departamentales en las que los entes territoriales amplíen su accionar como bancos de segundo piso o fuentes que representen créditos y préstamos a los entes territoriales. Así cierta manera prevalece la solidaridad a la par que la responsabilidad por cuenta de los adquirientes del crédito con los requisitos que el departamento exige al respecto. El buscar fondeo a las entidades municipales que hacen parte de los departamentos es un buen mecanismo de apalancamiento compartido en la que todos terminan siendo aportantes del proceso y de cierta manera capitalistas del fondo. Exponen Peña et al. $(1999,3)$ que:

\section{"Entre las causas que explican la crisis fi- nanciera de la mayoría de los departamen- tos, distritos y municipios pueden señalarse fenómenos como el decrecimiento de los ingresos tributarios relacionado con la difí- cil situación económica del país y, también, con el menor esfuerzo fiscal territorial; el incremento de los gastos de funcionamien- to sin relación con el comportamiento de los ingresos; la espiral del endeudamiento y los efectos de la corrupción."}

Una oportunidad de oro para la generación de ingresos para los departamentos tienen que ver con la promoción de inversiones en sectores estratégicos como el de energía, la infraestructura y minería, que bien manejados podrían representar sumas importantes para el departamento y las subregiones. En un momento en el que la ley de regalías no ha tenido definición plena, sería una interesante opción para definir una política pública en el sector minero que le permitiese ordenar el tema desde el marco legal hasta la consistencia económica en todos los frentes.
Es hora de que las políticas públicas entren a ordenar el esquema económico departamental y territorial, y no dejar la intervención estatal como un escenario de delegación cuando los problemas aparecen. Ortega $(2008,282)$ expresa que:

"Actualmente, cuando en Colombia y América Latina se debate sobre los problemas del desempleo, la pobreza, la calidad de vida y la falta de oportunidades que afectan a un gran número de la población, y cuando se presume que muchos de tales problemas tienen su explicación en las políticas macroeconómicas y regionales y en fenómenos internacionales, los estudios locales regionales cobran importancia en tanto que esta escala territorial se constituye en el principal espacio donde convergen las fuerzas de la economía y se construyen las bases de un nuevo ordenamiento internacional. En este marco de problemas y controversia cabe preguntarse sobre la pertinencia, relación y grado de responsabilidad que las políticas económicas regionales tienen sobre la situación."

En adelante un patrón característico de los departamentos del país estará por cuenta de la capacidad de inversión y capitalización de ingresos que se muevan en diferentes frentes. La majestuosidad de la gestión territorial dependerá no de la disposición a recibir o solicitar recursos del orden central sino de la fortaleza para atraer y buscar recursos frescos que irriguen la inversión privada y pública del departamento. También los municipios terminaran siendo solidarios de la situación y capitalizadores de los esfuerzos que en ellos se reproduzcan, para que la creación de tributos no sea la única etapa de negociación, sino una adicional a todas las posibilidades que un departamento bien manejado podrían brindar. Jolly (2005, 151-152) asume que:

"Al construir localmente las soluciones que les parecen las más adecuadas para responder a las necesidades de las poblaciones de las cuales son los mandatarios, volviéndose así los defensores de la gobernancia de sus territorios, alcaldes y gobernadores colom- 
bianos demuestran que, más allá de la descentralización .venida de arriba., el verdadero enjeu (reto) es la territorialización de la acción pública .desde abajo. He aquí, sin duda alguna, el principal desafío de orden político y administrativo que, al interior de los departamentos y municipios, afectan el desarrollo de una gestión pública más democrática y eficiente."

Los entes territoriales, departamentos y municipios, tienen una opción de lujo al repensarse como plataforma económica, tanto en lo que responde a su cercanía geográfica, como en interacción con los territorios que al frente tienen como vecinos, con los cuales igualmente se puede estar vislumbrando una especie de federalismo fiscal en el que temas negados como la generación de tributos compartidos pasen a ser de la consideración permanente, debido a la alteridad y reconfiguración de los mismos conforme las condiciones socioeconómicas. Razones que explican por qué debe pensarse en otra fórmula para la generación de recursos distinta a los tributos directos.

\section{Conclusiones}

El Estado debe ser quien abandere el camino que deben recorrer los entes territoriales en cuanto a la posibilidad de apreciar fuentes de recursos diferentes o por los menos relevantes para las administraciones locales y regionales. Es importante considerar al respecto, la trascendencia de convocar a organismos como el FMI con los cuales puedan analizarse a escala territorial estos temas, pero con la presencia precisamente de representantes de dichos lugares, para que no terminen siendo la discusión de un marco de recetas generales que no atiendan a la realidad dispar del país, y que por ende, fracasen.

Se considera que una de las metas que debe establecerse como marco de referencia para las administraciones territoriales es que estas determinen las apuestas y perspectivas que estimen conveniente en materia de generación de recursos. Es una forma de abajo hacia arriba de compatibilizar el esfuerzo fiscal y de manejo presupuestal, con las pretensiones que en la materia pudiese entender el Estado cen- tral. Para ello, el papel de las Secretarias de hacienda departamentales es altamente crucial por cuanto la interpretación de dicha tarea depende igualmente de la complementariedad que tenga ella con las que corresponden a cada nivel de la administración pública local.

Es probable que en la medida de las posibilidades el incremento de los en las administraciones territoriales, dependa igualmente de la disposición que tenga el Estado central para que éstas en correspondencia con interés estrictamente de orden estatal, se sirvan aprestarse en calidad de contratistas del mismo para que puedan ir creándose la idea que dentro del Estado igualmente hay que competir. Las posibilidades de mejoramiento están afincadas en las condiciones que tienen los entes territoriales para hacer sujetos de contratación con el Estado central en diferentes campos, pero para ello, se requiere sino un cambio de estrategia básica, la revisión profunda del desempeño que estos han tenido para poder alcanzar una participación importante con el Estado.

\section{Referencias}

Acto Legislativo 05 de 2011 (Julio 18). Por el cual se constituye el sistema general de regalías, se modifican los artículos 360 y 361 de la constitución política y se dictan otras disposiciones sobre el régimen de regalías y compensaciones. Congreso de Colombia: 1-7.

Afanador V., B. \& Beltrán, L. N. (2007). Economía pública colombiana y desempeño fiscal en el contexto de la globalización. Escuela superior de administración pública -ESAP-: 1-162.

Bonet, J. (2004). Descentralización fiscal y disparidades en el ingreso regional: la experiencia colombiana. En Documentos de Trabajo sobre economía regional No 49, Banco de la República, Centro de Estudios Económicos Regionales (CEER) Cartagena: 1-50.

Cadaval, M. (2005). Reseña de economía pública local de Luis Carames Vieitez. En Investigaciones Regionales, Asociación Española de Ciencia Regional, Alcalá de Henares (6): 229-232.

Cano B., R. L. (2007). Descentralización fiscal y eficiencia en los servicios sociales a nivel territorial. En Equidad y Desarrollo, Universidad de la Salle (8): 7-24.

Cárdenas M., Mejía, C. \& Olivera, M. (2006). La economía política del proceso presupuestal en Colombia. En Working papers series - documentos de trabajo No. 31. Banco Interamericano de Desarrollo- Fedesarrollo: 1-69.

Clavijo, S. \& Vera, A. (2010). Los desafíos fiscales de Colombia (2010-2014). ANIF, Bogotá: 1-36.

Contraloría General de la República-CGR- (2006). Evaluación de las transferencias intergubernamentales 1994-2005. Informe Social. Contraloría General de la República: 1-70. 
Decreto 111 DE 1996 (Enero 15). Por el cual se compilan la Ley 38 de 1989, la Ley 179 de 1994 y la Ley 225 de 1995 que conforman el estatuto orgánico del presupuesto. Congreso de Colombia. En Diario Oficial 4269; 1-49.

Departamento Nacional de Planeación -DNP- (2005). Capacidad fiscal de los gobiernos territoriales colombianos. Dirección de Desarrollo Territorial Sostenible: 1-56.

DNP -Departamento Nacional de Planeación- (2005). Dirección de Desarrollo Territorial Sostenible (2005). Análisis financiero y capacidad fiscal de las principales ciudades Colombianas Grupo de Análisis y al Financiamiento del Desarrollo Territorial -GAFDT-, Bogotá: 1-57.

García R., N. (2011). ¿La región del Pacifico?. En: Choco 7 días. edic.800: 3 .

Gómez H., B. (2007). La deuda externa territorial en Colombia: Evolución, impacto y análisis de la situación actual. En Revista Diálogo de Saberes (26): 117-143.

Guadarrama S., G. (2003). Gerencia Pública y Política Social en Latinoamérica. En Economía, sociedad y territorio, Vol. IV. (13): 127-162.

Hernández G., A. (2006).Evaluación de la gestión pública 2005. Programa por el buen uso de los recursos públicos Cuarto informe. Contraloría General de la República, Bogotá: 1- 55.

Jolly, J.F. (2005). Gobernabilidad territorial y descentralización en Colombia: ¿regir el territorio o gobernar los territorios? A propósito de la política pública de descentralización en Colombia entre 1982 y 2002. En Papel Político (18): 137-154.

Ley 819 de 2003 (julio 9). Por la cual se dictan normas orgánicas en materia de presupuesto, responsabilidad y transparencia fiscal y se dictan otras disposiciones. Congreso de Colombia Diario Oficial No. 45.243, de 9 de julio de 2003.

Ley 617 de 2000 (octubre 6). Por la cual se reforma parcialmente la Ley 136 de 1994, el Decreto Extraordinario 1222 de 1986, se adiciona la Ley Orgánica de Presupuesto, el Decreto 1421 de 1993, se dicta otras normas tendientes a fortalecer la descentralización, y se dictan normas para la racionalización del gasto público nacional. Congreso de la República. En Diario Oficial No. 44.188: 1-40.

Ley 225 de 1995 (diciembre 20). Por la cual se modifica la Ley Orgánica de Presupuesto. Congreso de Colombia. En Diario Oficial 42.157: 1-12.

Ley 179 de 1994 (diciembre 30). Por el cual se introducen algunas modificaciones a la Ley 38 de 1989 Orgánica de Presupuesto. Congreso de Colombia. En Diario Oficial 41.659: 1-32.

Ley 152 de 1994 (julio 15). Por la cual se establece la Ley Orgánica del Plan de Desarrollo. Congreso de Colombia. En Diario Oficial 41.450: 1-28.

Ley 80 de 1993 (octubre 28). Por la cual se expide el Estatuto General de Contratación de la Administración Pública. En Diario Oficial No. 41.094, del 28 de octubre de 1993: 1- 37.
Ley 42 de 1993 (enero 26). Sobre la organización del sistema de control fiscal financiero y los organismos que lo ejercen. Congreso de la República. En Diario Oficial No. 40.732: 1-35.

Ley 38 de 1989 (abril 21). Estatuto Orgánico del Presupuesto General de la Nación. Normativo del Presupuesto General de la Nación. En Diario Oficial 38.789: 1-33.

Makón, M. (2000). El modelo de gestión por resultados en los organismos de la administración pública nacional. En V Congreso Internacional del CLAD sobre la Reforma del Estado y de la Administración Pública, Santo Domingo, Re Dominicana, 24-27, octubre: 1-14.

Márquez A., Y. \& Silva R., J. (2008). Pensamiento económico con énfasis en pensamiento económico público. Escuela Superior de Administración Pública -ESAP- Bogotá: 147-184.

Ministerio de Hacienda y Crédito Público (2010). Estrategia económica y fiscal 2010-2014.

Ministerio de Hacienda y Crédito Público- MHCP- (2010). Proyecto de Presupuesto General de la Nación 2011 "Hacia la estabilidad macroeconómica" Dirección General del Presupuesto Público Nacional República de Colombia: 1-27.

Montecinos, E. (2005). Los estudios de descentralización en América Latina: una revisión sobre el estado actual de la temática. En Revista eure, Vol. XXXI (93): 73-88.

Muñoz, N. J. (2009). Las regiones más allá del ajuste fiscal. En Diario Portafolio, No 3353: 39.

Muñoz G. O. H. (2002). La gerencia pública y su importancia en el proceso de planeación y gestión del desarrollo local en los municipios colombianos. En Revista Tendencias, Revista de la Facultad de Ciencias Económicas y Administrativas. Universidad de Nariño, Vol III (2): 27-56.

Ortega-M., J. E. (2008). Crítica a las políticas de desarrollo regional en Colombia en el marco de la globalización: el caso del departamento de Córdoba. En Economía, Sociedad y Territorio, vol. VIII (26): 281-312.

Peña J., E., Tovar, M.A., Villamil L., E., \& Giraldo M., E. (1999). Fondo nacional de pensiones de las entidades territoriales FONPET - Ley 549 de 1999. Ministerio de Hacienda y Crédito Público: 1-30.

Rentería, C. y Echeverry, J. C.(2006). Presupuestando en Colombia: buscando la sostenibilidad fiscal a través del presupuesto. Serie Gestión Pública 61. ILPES -CEPAL - ONU.

Restrepo Q., G. y Álvarez V., D. (2005). Ley 617 de 2000 y su impacto fiscal territorial. Centro Regional de Estudios Económicos CREE Medellín.

Zapata G., J., Acosta, O. L. \& González, A. (2001). Evaluación de la descentralización municipal en Colombia: ¿Se consolidó la sostenibilidad fiscal de los municipios colombianos durante los años noventa? Dirección de Desarrollo Territorial del DNP. -Departamento Nacional de Planeación-. Dirección de Estudios Económicos. En Documento 165: 1-86. 
